\title{
Acesso à educação e à tecnologia: desafios em tempos de pandemia
}

\author{
Juliana Ferreira dos Santos* \\ Antônio Fernandes Góes Neto** \\ Patrícia Farias Coelho***
}

\section{Resumo}

A pandemia ocasionada pela Covid-19 alterou todo o contexto das relações sociais e resultou em mudanças significativas no cotidiano da humanidade. Autoridades supranacionais da saúde optaram pelo distanciamento social, afetando dessa maneira a educação, obrigando as escolas a se readaptarem ao novo cenário de salas de aula virtuais, nomeado pelo governo de Ensino Remoto Emergencial (ERE), para diferenciar das ações do Ensino a Distância (EaD). O objetivo geral desta pesquisa foi apresentar as mudanças que ocorreram no nosso país com a determinação da quarentena. Propomos dois objetivos específicos, a saber: (i) compreender como o ensino básico teve de migrar para o ensino remoto emergencial, devido à Covid-19; e (ii) depreender como a educação, que é um direito de todos, foi garantida pelo governo na pandemia.

Palavras-chave: Covid-19. Pandemia. Tecnologia. Ciência. Educação básica.

* Doutoranda em Educação pela Faculdade de Educação da Universidade de São Paulo. São Paulo-SP. Endereço eletrônico:jubahia@usp.br. Lattes: http:/ / lattes.cnpq.br/7453696702571127.

** Doutorando em Educação pela Faculdade de Educação da Universidade de São Paulo. São Paulo-SP. Endereço eletrônico: http://lattes.cnpq. br/9583425947146627 ORCid: 0000-0002-5312-4168.

*** Professora da Universidade Metodista de São Paulo (UMESP) e da Universidade Ibirapuera (UNIB). Possui auxílio da FAPESP ao Projeto de Pesquisa, intitulado "Formação de Professores e Tecnologias Digitais aplicadas à Educação”. Processo No. 2018/07133-0. Doutora em Comunicação e Semiótica pela Pontifícia Universidade Católica de São Paulo (PUC-SP). Endereço eletrônico: patriciafariascoelho@gmail.com. ORCid: https://orcid.org/00000002-1662-1173. 


\section{Access to education and technology: challenges in pandemic times}

\section{Abstract}

The pandemic caused by Covid-19 changed the whole context of social relations and resulted in significant alterations in the daily lives of humanity. Supranational health authorities opted for social distancing, thus affecting education, which was forced to adapt to the new scenario of virtual classrooms, appointed by the government of Emergency Remote Education (ERE), to differentiate from Distance Learning actions (EaD). The general objective of this research was to present the changes that occurred in our country with the determination of the quarantine. We propose two specific objectives, namely: (i) understand how basic education had to migrate to remote emergency education because of Covid-19; and (ii) understand how education, that is a right for all, was guaranteed by the government in the pandemic.

Keywords: Covid-19. Pandemic. Technology. Science. Basic education.

\section{Acceso a la educación y la tecnología: desafíos en tiempos de pandemia}

\section{Resumen}

La pandemia causada por Covid-19 cambió todo el contexto de las relaciones sociales y resultó en cambios significativos en la vida diaria de la humanidad. Las autoridades sanitarias supranacionales optaron por el distanciamiento social, afectando así a la educación, que se vio obligada a adaptarse al nuevo escenario de aulas virtuales, designado por el gobierno de Emergencia Educación Remota (ERE), para diferenciar las acciones de Educación a Distancia (EaD). El objetivo general de esta investigación fue presentar los cambios ocurridos en nuestro país con la determinación de la cuarentena. Proponemos dos objetivos específicos, a saber: (i) comprender cómo la educación básica tuvo que migrar a la educación remota de emergencia debido a Covid-19; y (ii) comprender cómo la educación, que es un derecho para todos, fue garantizada por el gobierno en la pandemia.

Palabras Claves: Covid-19. Pandemia. Tecnología. Ciencias. Educación básica. 
“[...] em função dessa pandemia, o ensino presencial foi abruptamente privado dos estudantes em seus mais diversos níveis de ensino, pois assim como toda a sociedade, a efeito das políticas públicas de saúde adotadas no país estão em período de isolamento social, evitando qualquer tipo de aglomeração, como principal medida para reduzir o contágio pelo vírus” (MARQUES, 2020, p. 32, grifos nossos).

\section{Introdução}

A história da humanidade traz registros de pandemias que assolaram o mundo como, por exemplo, a gripe espanhola, a peste negra e a varíola, que se espalharam e causaram muitas mortes.

Atualmente vivemos uma pandemia que surgiu em dezembro de 2019, por meio do vírus SARS-CoV-2, conhecido como novo coronavírus, a Covid-19. O vírus surgido em Wuhan (China) se alastrou a outros países e continentes, causando um isolamento mundial. Devido ao seu alto grau de contágio, que acarretou em mudanças drásticas em várias áreas da sociedade, foram se alterando não somente os hábitos das pessoas, como também a economia, a saúde e a política, na medida em que as notícias sobre a pandemia instalavam um cenário de insegurança diante dessa ameaça, até então desconhecida e, tal como afirmado na epígrafe de Marques (2020), modificou as relações sociais e afetou principalmente a área da Educação.

Nesse contexto pandêmico, as relações sociais se redefiniram e as pessoas tiveram de se isolar para se protegerem e evitar a propagação ainda maior do vírus. Dentre as muitas áreas afetadas, o espaço físico das escolas, enquanto ambiente social plural, como espaço de saber e ícone da educação formal (DIAS; PINTO, 2020), precisou se redefinir, fazendo com que a sala de aula migrasse para o ambiente virtual, impondo desafios para muitos pais, mães e demais responsáveis que contavam com o espaço escolar como parte essencial da rotina dos filhos, seja para aprendizado e convivência, seja para alimentação.

Castells (2011) defende que a sociedade digital é uma realidade em muitas partes do mundo, no entanto, no Brasil, há ainda esferas que carecem de ferramentas de acesso à informação, prin- 
cipalmente na área da Educação. Há também regiões com menos acesso a tais ferramentas, por conta da baixa oferta de conexão à internet, ou mesmo à telefonia, como, por exemplo, a região da Amazônia (COSTA; COELHO; TAVARES, 2020).

Apresentado o contexto da Covid-19, ressaltamos que a escola do ensino básico no formato presencial, como era conhecida e utilizada por grande parte dos alunos e professores, foi obrigada a se readequar ao ensino remoto emergencial, doravante ERE (OLIVEIRA et al., 2020). O conceito do ERE surge para diferenciar-se da educação a distância, a $\mathrm{EaD}$, que já é uma realidade em nosso país. Dessa forma, o ensino remoto apareceu como uma solução temporária para continuar as atividades pedagógicas nas instituições de ensino, tendo como principal ferramenta o uso da internet.

Ainda que as Tecnologias para Aprendizagem já fizessem parte de alguns dos currículos das escolas públicas e privadas no ensino básico do País, elas eram, muitas vezes, consideradas como ferramentas isoladas e não como aparatos que integravam as aulas, tornando-se efetivamente digitais (COSTA; COELHO; TAVARES, 2020).

A partir desse novo panorama social, histórico e econômico, esta pesquisa parte desses questionamentos para refletir sobre as mudanças ocorridas em nosso país com a determinação da quarentena em março de 2020, que obrigou a reestruturação da educação básica e superior, com base em alguns desafios presentes, principalmente para a escola do ensino básico. Temos assim dois objetivos específicos, a saber: (i) verificar como o ensino básico teve de migrar para o ensino ERE, devido à Covid-19; e (ii) compreender como a educação, que é um direito da criança e do adolescente, foi garantida em tempos de pandemia.

A justificativa deste trabalho deve-se ao momento pandêmico instalado no Brasil, fazendo com que professores e alunos mudassem a sua prática pedagógica, emergindo do presencial para o ambiente digital, tendo de forçosamente entender quais são as características específicas para o trabalho virtual.

O arcabouço teórico utilizado neste estudo foram as pesquisas bibliográficas na área da Educação em momentos de pandemia, des- 
tacando os estudos de Marques (2020), Dias e Pinto (2020) e Oliveira et al. (2020), e as pesquisas sobre tecnologias de Prensky (2001), Costa, Coelho e Tavares (2020) e Couto, Couto e Cruz (2020).

$\mathrm{O}$ artigo foi dividido em três partes. Em um primeiro momento, apresentaremos a metodologia proposta neste trabalho. A seguir, esclareceremos sobre como o impacto da pandemia afetou o ensino básico, fazendo com que algumas escolas migrassem para o ERE, e, por fim, contextualizaremos como a educação básica, que é um direito, foi garantida em tempos de pandemia.

\section{Metodologia}

A revisão bibliográfica, segundo Gil (2008), é desenvolvida com base em material já elaborado, constituído principalmente de livros e artigos científicos, tendo, no caso deste artigo, uma abordagem qualitativa, referindo-se à organização, estruturação e análise das informações referentes às interfaces entre educação e tecnologia no contexto da pandemia do novo coronavírus.

As referências selecionadas, coletadas e citadas neste estudo contemplam autores num período atual do surgimento da Covid-19. A partir da inserção dos termos das quatro palavras-chave: Covid-19, pandemia, educação e tecnologia, foram realizadas pesquisas nas plataformas Google e Scholar Google (Google Acadêmico) a fim de encontrar os resultados e selecionar o que pudesse servir como base para esta pesquisa, no período de 8 de agosto de 2020 a 8 de novembro de 2020.

O material utilizado foi definido a princípio por título, e posteriormente pela leitura do resumo, da introdução e da conclusão para verificação da adequação do tema. Assim, a estrutura desse estudo é composta pelas seguintes etapas: a) compreensão do conceito do ensino ERE na pandemia da Covid-19; b) as mudanças da didática do ensino presencial para o ensino virtual em tempos de pandemia; c) os impactos da dificuldade de acesso na educação brasileira em 2020; e d) a compreensão das tecnologias da informação que estão sendo utilizadas como plataformas para o uso no cotidiano escolar brasileiro. 


\section{Contextualização no ensino básico no momen- to pandêmico e o surgimento do ensino remoto emergencial e suas caraterísticas}

Inicialmente, o vírus da Covid-19 foi transmitido por pessoas que iam e vinham em viagens de avião, barco, carro, dentre outros, exigindo que a Organização Mundial da Saúde (OMS) determinasse quarentena e fechamento de fronteiras, com o intuito de controlar o aumento exponencial de infectados. As pessoas podem se infectar através do toque, do aperto de mãos contaminadas, gotículas de saliva, espirro, tosse, catarro e também por objetos ou superfícies contaminadas, como celulares, mesas, talheres, maçanetas, brinquedos, teclados de computador etc. No Brasil, o primeiro caso foi registrado no dia 26 de fevereiro de 2020 (PINHEIRO; RUPRECHT, 2020). De acordo com as últimas notícias da (OMS), no dia 8 de novembro 2020, o País já registrava 174.515 óbitos.

Com o surgimento e a expansão da pandemia, a OMS proibiu as pessoas de saírem de casa. Com isso, as escolas deixaram a rotina presencial e migraram $100 \%$ para o virtual, proibindo professores e alunos de frequentarem as escolas, inicialmente por uma quarentena que durou cerca de 15 dias, mas que foi se prologando por mais 15 dias, até chegar a um período de seis meses.

Consequentemente, com o isolamento social causado pela pandemia, as instituições de ensino tiveram de readequar as suas disciplinas, sua metodologia, as formas de realizar reuniões, as postagens das notas, ou seja, foram obrigadas a reorganizar toda a sua didática e estrutura. Dessa forma, as instituições de ensino tiveram de explorar, ensinar e contextualizar o conteúdo a partir de distintos aparatos tecnológicos, por meio de aulas síncronas, realizadas em tempo real, e assíncronas, que acontecem no tempo do aluno (COUTO; COUTO; CRUZ, 2020).

A partir desse panorama, torna-se relevante diferenciar o conceito do ERE do ensino EaD, que já acontecia no Brasil, no ensino superior, desde 2010 por meio da resolução no 1/2016. Embora na prática possam ser ações muitas vezes semelhantes, a EaD 
não é e nem era novidade no território nacional, sendo caracterizada, conforme explica a Resolução nº 1/2016 (BRASIL, 2016):

[...] como modalidade educacional na qual a mediação didático-pedagógica, nos processos de ensino e aprendizagem, ocorre com a utilização de meios e tecnologias de informação e comunicação, com pessoal qualificado, políticas de acesso, acompanhamento e avaliação compatíveis, entre outros, de modo que se propicie, ainda, maior articulação e efetiva integração e complementariedade entre a presencialidade e a virtualidade "real", o local e o global, a subjetividade e a participação democrática nos processos de ensino e aprendizagem em rede, envolvendo estudantes e profissionais da educação (professores, tutores e gestores), que desenvolvem atividades educativas em lugares e/ou tempos diversos.

O documento citado destaca os aspectos fundamentais para que a EaD ocorra. Nota-se que ela ultrapassa a mera utilização de Tecnologias Digitais da Informação e Comunicação, doravante TDIC. Também vale ressaltar que as TDIC já vêm contribuindo para as novas práticas de ensino básico há algum tempo em nosso país, antes do período pandêmico, uma vez que algumas escolas já se preocupavam em acolher os nativos digitais (PRENSKY, 2001), que são os já nascidos e imersos na cultura digital e que já cresceram fazendo uso das TDIC ao longo da sua prática cotidiana.

Ainda que alguns alunos já utilizassem os aparatos tecnológicos nas suas práticas diárias, muitas escolas da educação básica no Brasil não utilizam as TDIC como ferramentas didáticas. Assim, o MEC publicou o Despacho de 29 de maio de 2020, que homologa o Parecer CNE/CP n ${ }^{\circ}$ 5/2020 (BRASIL, 2020b) do Conselho Pleno Nacional da Educação (CNE), aprovando a reorganização do calendário escolar e permitindo a aplicação de atividades não presenciais, uma vez que o ensino básico teve de migrar para o digital, exigindo que professores e alunos passassem a utilizar as TDIC.

Evidenciado esse novo cenário mundial, destacamos que as escolas do ensino básico que migraram para o ensino online passaram a ter suas práticas nomeadas como ERE, pois tiveram de transportar, reformar e repensar suas aulas no ambiente virtual. Ressal- 
tamos que uma aula presencial não é simplesmente transportada para uma aula na modalidade virtual, pois o professor deve entender as particularidades do ambiente digital a fim de elaborar um plano de aula interessante, dialógico e exitoso.

Dessa forma, conforme defendem Oliveira et al. (2020), apesar dos esforços públicos e do empenho dos docentes para acolher os alunos, há ainda muitas dificuldades em sua realização plena, uma vez que o País tem vasta extensão territorial e possui muitas diferenças sociais. Além disso, na formação docente inicial (graduação), muitos professores não tiveram a formação em tecnologia digital, pois não havia disciplinas dedicadas a essa temática.

Destacamos que, atualmente, algumas faculdades já acrescentaram a disciplina Tecnologia e Educação, ministrada nos cursos de licenciatura, principalmente nos de pedagogia. Dessa forma, observamos que em todos os espaços da sociedade sentimos a presença da tecnologia no dia a dia das pessoas, especialmente nas crianças, que já nasceram conectadas ao mundo digital.

Há, contudo, um agravante, uma vez que a extensão de nosso país revela uma internet instável ou até mesmo quase inexistente em várias regiões. Além disso, como o ensino ERE obrigou muitas famílias a utilizarem o mesmo aparato tecnológico, como, por exemplo o celular ou o notebook, isso causou vários tipos de problemas, pois havia mais de uma criança no mesmo domicílio frequentando a escola regularmente no mesmo horário que os seus irmãos.

Essas transformações impostas pela Covid-19 nas práticas do professorado para o uso da tecnologia digital já vinham sendo destacadas pela Base Nacional Comum Curricular, BNCC, alertando sobre a relevância dos educadores compreenderem as necessidades advindas do século XXI para a utilização das TDIC em salas de aulas como uma ferramenta que auxilia nas práticas pedagógicas, pois:

A cultura digital perpassa todos os campos, fazendo surgir ou modificando gêneros e práticas. Por essa razão, optou-se por um tratamento transversal da cultura digital, bem como das TDIC [Tecnologias Digitais da Informação e Comunicação], articulados a outras dimensões nas práticas em que aparecem (BRASIL, 2018, p. 67). 
Conforme apontam Coelho, Mota e Azevedo (2020), pode-se dizer que tanto as TDIC quanto a cultura digital já vinham sendo debatidas, de forma transversal, desde a BNCC (BRASIL, 2018), e sua aplicabilidade tornou-se efetiva após a proliferação da Covid-19. Partindo desse princípio, muitos docentes, principalmente os do ensino básico, não tiveram a formação inicial na graduação para o uso das tecnologias, que já deveriam estar testando ou utilizando algum tipo de tecnologia digital em sala de aula, uma vez que isso está previsto na BNCC. No entanto, nem sempre as didáticas docentes representam a realidade que ocorre no cotidiano escolar em nosso país, principalmente pelas dificuldades de materiais de acesso às ferramentas necessárias, como microcomputadores, tablets e smartphones apontados por Couto, Couto e Cruz (2020). Ainda segundo os mesmos autores:

\footnotetext{
Professores e alunos matriculados em cursos antes presenciais, migraram para atividades educacionais em rede. Conectando, profissionais da educação produzem e distribuem conteúdos, acompanham, orientam, avaliam e estimulam seus alunos. Muitos estão repensando e recriando metodologias ativas mais sedutoras e desenvolvendo ambientes digitais mais amigáveis e com interações crescentes (COUTO; COUTO; CRUZ, 2020, p. 209).
}

Sobre o uso e recriação das ditas metodologias ativas em meio a essa readequação das escolas, os autores Couto, Couto e Cruz (2020), afirmam que apesar das dificuldades de acesso às tecnologias da educação, desde a implementação da EaD em 2010 tem havido um notório esforço das instituições no sentido de engajar docentes e discentes nas aulas virtuais e ressignificá-las dentro das limitações do ambiente digital que alguns professores e alunos não dominam.

Essa filosofia do aprender fazendo é aceita por muitos educadores como um caminho eficaz, porém apresenta desafios de acompanhamento no contexto de ensino remoto, dificultando a observação atenta do professor a cada aluno, no modelo muitas vezes conhecido como de tutoria. Conforme explica Tardif (2002), tais dificuldades também se devem à ausência de formação docente para tal 
multiplicidade de ambientes virtuais em boa parte da oferta de cursos de licenciaturas no País, sendo muitos deles no formato EaD.

Assim, evidenciamos que não somente educadores, principalmente do ensino básico, como também pais, mães e responsáveis vêm apresentando estranhamentos em relação à implementação do ERE, haja vista ter modificado a rotina de muitas famílias acostumadas a verem seus filhos no espaço escolar por um ou dois turnos. Além dessa mudança, que idealiza um certo padrão familiar, muito aproximado das propriedades privadas de pessoas de classe média no País e que não representa boa parte das famílias brasileiras de baixa renda, algumas pessoas passaram a ter contato direto com a rotina escolar dos seus filhos, ao mesmo tempo em que foram obrigadas a readequarem as suas rotinas de trabalho para dar mais atenção aos estudos deles (OLIVEIRA et al., 2020).

Dessa forma, neste tópico foi possível verificar a contextualização do surgimento na pandemia no País, evidenciando a implementação, expansão e a dificuldade na implementação do ERE no ensino básico no Brasil, que ainda não ocorria na modalidade virtual.

\section{Educação é um direito garantido pela constitui- ção: como esse direito foi garantido em tempos de pandemia?}

Em nosso país, a educação é um direito de todos e dever do Estado. Segundo a Constituição, a educação deve ser garantida pelo "Estado e pela família, pois será promovida e incentivada com a colaboração da sociedade, visando ao pleno desenvolvimento da pessoa, seu preparo para o exercício da cidadania e sua qualificação para o trabalho" (BRASIL, 1988, p. 8).

Dessa forma, conforme a Constituição Federal de 1988, as instituições básicas devem garantir a formação integral dos discentes, e esse direito deve ser assegurado, ainda que o País esteja vivendo um momento pandêmico, garantindo que os alunos tenham acesso ao ensino, para se constituírem como cidadãos e exercerem a sua cidadania a fim de cumprir com seus direitos e deveres na nossa sociedade. 
Com base nessas premissas garantidas na Constituição Federal de 1988, o CNE homologou um ciclo emergencial para a diminuição dos impactos negativos durante a pandemia na educação, causados pelo afastamento social e pela proibição de aulas na modalidade presencial. Em razão da longa duração da suspensão das atividades educacionais de forma presencial, as escolas emergiram quase que $100 \%$ para a modalidade remota. Portanto, o órgão destacou que, independentemente da estratégia adotada, as redes de ensino deveriam: i) ter como finalidade o atendimento dos direitos e objetivos de aprendizagem previstos para cada série/ano; ii) assegurar e manter o padrão de qualidade previsto em leis (Lei de Diretrizes e Bases da Educação e Constituição Federal); iii) cumprir a carga horária mínima prevista na LDB de 200 horas; iv) evitar retrocessos de aprendizagem por parte dos estudantes e perdas do vínculo com a escola; v) observar a realidade e os limites de acesso dos estabelecimentos de ensino e dos estudantes às diversas tecnologias, sendo necessário considerar propostas inclusivas e que não reforcem ou aumentem a desigualdade de oportunidades educacionais; e vi) garantir uma avaliação equilibrada dos estudantes, assegurando as mesmas oportunidades a todos, a fim de evitar o aumento da reprovação e do abandono escolar (BRASIL, 2020c).

Apresentado esse contexto neste tópico, buscaremos verificar como o artigo 205 sustenta a educação na Constituição Federal de 1988, garantida no momento pandêmico. Em tempos de pandemia, Dias e Pinto (2020) explicam que os setores da educação têm se adequado com muitas dificuldades para garantir esse direito. Mesmo com a expansão da Covid-19, o Estado, de modo a garantir o direito à educação, publicou novas resoluções em que propõem uma rotina da sala de aula que migra do ambiente presencial para a modalidade virtual. Assim sendo, a resolução busca garantir aos discentes a mesma qualidade de aprendizagem que na modalidade presencial, uma vez que o intuito era o de que professores e alunos acessassem por meios de diferentes dispositivos móveis os conteúdos das disciplinas referentes a cada série, oferecendo, assim, a aprendizagem dos alunos. Conforme explica Marques (2020, p. 33): 
Diante desse contexto de pandemia no Brasil e no mundo, em que o crescimento de casos foi e vem gradativamente crescendo no Brasil, uma das medidas assumidas pela Secretaria Estadual de Educação do Paraná e tanto pela Secretaria Estadual de Educação de São Paulo foram desenvolvendo ações como meios alternativos ao processo de ensino e aprendizagem, promovendo aulas na modalidade de Educação a Distância (EaD), onde estudantes, professores e todos os envolvidos com o processo escolar em isolamento social pudessem ter acesso, e dessa forma dar continuidade ao ano letivo em curso pelos aplicativos da google classroom, com sistemas de aulas e organização de salas de aulas, sendo transmitidos pela TV e pelo YouTube nas redes e canais que foram contratados para prestar o serviço que atingisse o maior número possível da comunidade escolar, dessa forma, buscando minimizar os impactos da pandemia sobre a Educação.

Dentro desse panorama, para garantir o direito dos alunos à educação, professores e diretores passaram a utilizar as redes sociais e os canais do Youtube. Além disso, foram utilizadas novas metodologias alternativas de ensino do mundo digital, como a plataforma Google Classroom já mencionada, que permitiu aos alunos o acesso aos conteúdos, além de possibilitar uma nova prática do professor. Destacamos, assim, que as aulas on-line, como já citado anteriormente, poderiam ser tanto síncronas, que ocorrem em tempo real com os alunos, como assíncronas, sob a forma de aulas gravadas.

Apoiados nas palavras dos pesquisadores Amaku et al. (2021), podemos depreender que as aulas assíncronas carecem de uma interação maior entre alunos e professores para que o método seja aplicado com eficiência, já que não se tem uma perspectiva de normalização das atividades devido ao crescente número de vítimas do vírus no Brasil, principalmente no Estado do Amazonas (CRUZ, 2020).

Marques (2020), complementando a ideia de Amaku et al., explica que com o ensino ERE há uma necessidade maior do auxílio dos pais, mães e responsáveis para atender os alunos. $\mathrm{O}$ mais importante foi que essas plataformas digitais permitiram a garantia do direito à aprendizagem, conforme previsto no artigo 205 da Constituição Federal de 1988. 
Desse modo, a Constituição e a LDB da Educação preconizam o ensino como direito, e reforçam o princípio da equidade de condições para o acesso e permanência na escola (BRASIL, 2010; BRASIL, 1996). Há uma preocupação, por parte do governo, com a possibilidade de os alunos, principalmente do ensino básico, estarem perdendo a referência com os colegas, com a escola e com o professor. Depreendemos que há uma pressão da sociedade para que as escolas retornem para a modalidade presencial em fevereiro de 2021. No entanto, até o presente momento, 25 de janeiro de 2021, não saiu nenhuma resolução afirmando como seria essa volta às aulas.

Verificamos, assim, que os órgãos governamentais responsáveis pela educação buscaram garantir aos alunos o direito à educação, permitindo aos discentes continuarem tendo acesso aos conteúdos previstos no currículo do ano de 2020 por meio do ERE. Dessa forma, as instituições de ensino precisaram se reinventar para atrair e manter os números de alunos matriculados já que, segundo o MEC,quase 650 mil alunos abandonaram suas matrículas escolares na rede pública de ensino, em 2020, tendo assim um grande número de evasão, conforme UOL (2020).

Essas instituições procuraram dar um treinamento contínuo aos seus professores na modalidade virtual, para que o direito à educação fosse garantido aos seus alunos. Além disso, com o treinamento on-line, foi possível aos professores aprenderem e compreenderem as potencialidades e possibilidades pedagógicas do ambiente digital para essa nova realidade imposta pelo coronavírus. Dessa forma, neste tópico foi possível averiguar como o artigo 205 da Constituição Federal garantiu o direito à educação a todos os estudantes no momento pandêmico.

\section{Considerações finais}

Neste estudo buscamos compreender as mudanças advindas da pandemia da Covid-19, principalmente no campo da educação básica brasileira, mostrando as soluções encontradas pelo governo para garantir o direito à educação a todos os alunos do País. Evi- 
denciamos neste estudo a dificuldade que alguns docentes tiveram em dominar as ferramentas digitais pela falta de formação inicial na graduação (PIMENTA, 2010), o que dificultou a migração desse profissional da aula presencial para a modalidade virtual.

O primeiro objetivo foi alcançado, pois foi possível compreender como, a partir do surgimento da Covid-19, o ensino básico migrou para o ensino remoto utilizando as potencialidades da Ead. Dentre as dificuldades impostas pela Covid-19, ressaltamos o fato de o professor precisar entender que não se tratava apenas de uma transmutação da aula presencial para o virtual, mas que deveria aprender, compreender e utilizar as especificidades do ensino virtual.

O segundo objetivo também foi alcançado, pois foi possível verificar como o artigo 205 da Constituição Federal de 1988 garantiu a educação como um direito de todos, nos tempos de pandemia. Dessa forma, a proposta deste estudo partiu das reflexões da recomendação oficial de um modelo de educação que agregasse aos docentes e discentes a evolução tecnológica, sendo um ensino-aprendizagem de natureza adaptativa e emergencial, no qual a tecnologia possibilitaria a continuação das aulas de forma remota, evitando a perda do ano letivo.

Tendo em vista esse contexto, a pesquisa revelou algumas estratégias de reinvenção da educação, enaltecendo a importância do papel do professor na realização de novos processos educacionais, que têm evidenciado desigualdade no acesso à tecnologia digital por não possuírem em sua formação inicial nenhuma disciplina específica para o uso das tecnologias digitais. Atualmente, algumas instituições de ensino superior, como por exemplo, a Universidade Metodista de São Paulo, já inseriram a disciplina educação e tecnologia na grade curricular, no curso de pedagogia.

Compreendemos que nesse momento em que vivemos é fundamental investir em capacitação dos professores, ou seja, na formação continuada de professores (NÓVOA, 1992), possibilitando aprendizado e entendimento sobre o universo digital, especialmente as tecnologias móveis e seus aplicativos. Com o investi- 
mento na formação continuada dos professores, a educação poderá se reinventar em suas práticas pedagógicas com o uso das TDCI, principalmente após a crise do coronavírus. Embora alguns professores critiquem e rejeitem trabalhar na modalidade virtual, esta mostrou sua eficiência e garantiu o direito à educação dos discentes nessa crise mundial.

O nosso trabalho não foi uma pesquisa final, mas uma proposta que permite reflexões. Dessa forma, apresentados os nossos objetivos, ressaltamos que o arcabouço teórico foi suficiente, como também a nossa metodologia, que propôs um estudo teórico acerca do tema. Sabemos que ainda teremos muito para ler, discutir e apreender sobre esse momento pandêmico e seus efeitos positivos e negativos na área da educação, já que ainda não se findou a pandemia, embora já tenham sido aprovadas as vacinas em 17 de janeiro de 2021, a Coronavac, do laboratório Chinês Sinovac, em parceria com o Instituto Butantan, da Universidade de São Paulo-USP, e a vacina AstraZeneca, do Laboratório de Oxford, em parceria com a Fundação Oswaldo Cruz-FIOCRUZ.

Ainda que as vacinas tenham sido aprovadas, não há informações concretas até o dado momento, em janeiro de 2021, de quando as crianças serão efetivamente vacinadas e poderão voltar às aulas presenciais, já que as aulas remotas não foram escolha da maioria, mas sim uma imposição causada pelo aumento do vírus no Brasil e em todo o mundo.

Acreditamos ainda, fundamentados em Amaku et al. (2021), Costa, Coelho e Tavares (2020) e Marques (2020), que a situação educacional futura sofrerá grandes impactos, sejam negativos ou positivos, pois muitos jovens e adultos que faziam parte do ensino básico não estavam preparados para o ensino à distância e tiveram de se adaptar. Muitas vezes, sem grande sucesso. Cremos que essas grandes dificuldades e lacunas na aprendizagem somente poderão ser estudadas e analisadas daqui a cinco anos, ou mais. Aguardamos o futuro, aguardamos a vacina, aguardamos a normalidade, aguardamos a volta à escola. 


\section{Referências}

AMAKU, Marcos; COVAS, Dimas Tadeu; COUTINHO, Francisco Antônio Bezerra; AZEVEDO NETO, Raymundo Soares; STRUCHINER, Claudio; WILDER-SMITH, Annelies; MASSAD, Eduardo. Modelling the test, trace and quarantine strategy to control the COVID-19 epidemic in the state of São Paulo, Brazil. Infectious Disease Modelling, v. 6, p. 46-55, 2021.

BRASIL. Constituição da República Federativa do Brasil. Brasília: Planalto, 1988. Disponível em: http://www.planalto.gov.br/ccivil_03/constituicao/constituicao.htm. Acesso em: 24 jul. 2020.

BRASIL. Decreto $\mathrm{n}^{\circ}$ 2.494, de 10 de fevereiro de 1998. Disponível em:_http:// www.planalto.gov.br/ccivil_03/decreto/D2494.htm. Acesso em: 22 jul. 2020.

BRASIL. Decreto ${ }^{\circ}$ 9.057, de 25 de maio de 2017. Disponível em: http:/ / www. planalto.gov.br/ccivil_03/_Ato2015-2018/2017/Decreto/D9057.htm. Acesso em: 28 set. 2020 .

BRASIL. Ministério da Educação. Base Nacional Curricular Comum. Brasília: Conselho Nacional da Educação, 2018. Disponível em: http://basenacional comum.mec.gov.br/a-base. Acesso em: 21 out. 2020.

BRASIL. Ministério da Educação. Conselho Nacional de Educação. Resolução $\mathbf{n}^{\mathbf{o}}$ 1, de 11 de março de 2016. Estabelece Diretrizes e Normas Nacionais para a Oferta de Programas e Cursos de Educação Superior na Modalidade a Distância. Brasília, DF, 2016. Disponível em: http://portal.mec.gov.br/docman/marco-2016-pdf/35541-res-cne-ces-001-14032016-pdf/file. Acesso em: 21 out. 2020.

BRASIL. Ministério da Educação. Portaria no 343, de 17 de março de 2020. Dispõe sobre a substituição das aulas presenciais por aulas em meios digitais enquanto durar a situação de pandemia do Novo Coronavírus - COVID-19. Diário Oficial da União, Brasília, DF, 2020a. Disponível em: https://www.in.gov.br/en/ web/dou/-/portaria-n-343-de-17-de-marco-de-2020-248564376. Acesso em: 21 out. 2020 .

BRASIL. Ministério da Educação. Conselho Nacional de Educação. Parecer $\mathbf{n}^{\mathbf{o}}$ 5/2020. Reorganização do Calendário Escolar e da possibilidade de cômputo de atividades não presenciais para fins de cumprimento da carga horária mínima anual, em razão da Pandemia da COVID-19. Brasília, DF, 2020b. Disponível em: http://portal.mec.gov.br/index.php?option=com_docman\&view=downloa$\mathrm{d} \&$ alias $=145011-$ pcp005-20\&category_slug $=$ marco-2020 pdf\&Itemid $=30192$. Acesso em: 21 out. 2020. 
BRASIL. Ministério da Educação. Parecer CNE/CP No: 5/2020. Reorganização do Calendário Escolar e da possibilidade de cômputo de atividades não presenciais para fins de cumprimento da carga horária mínima anual, em razão da Pandemia da COVID-19. Brasilia: Conselho Nacional de Educação, 2020c. Disponível em: http://portal. mec.gov.br/index.php?option $=$ com_docman\&view $=$ download\&alias $=145011$-pcp005-20\&category_slug=marco- -2020-pdf\&Itemid=30192. Acesso em 11 jun. 2020.

BRASIL. Presidência da República. Lei N. 9.394 de dezembro de 1996. Estabelece as diretrizes e bases da educação nacional. Brasília: Casa Civil, 1996.

BRASIL. Presidência da República. Lei N. 9.394 de dezembro de 1996. Estabelece as diretrizes e bases da educação nacional. Brasília: Casa Civil, 2010.

CASTELLS, M. A sociedade em rede. Tradução de Roneide Venâncio Majer. São Paulo: Paz e Terra, 2011.

COELHO, Patrícia M. F.; MOTTA, E. L. O.; AZEVEDO, A. B. Narrativas digitais e educação: estudo de caso de postagens no Facebook sobre o Programa Faróis do Saber da prefeitura de Curitiba-PR. AGON - Revista Internazionale Di Studi Culturali, Linguistici e Letterari, v. 24, p. 177-214, 2020.

COSTA, Marcos R. M.; COELHO, Patrícia M. F.; TAVARES, S. M. N. Potencialidades educacionais do Wattpad: problematizando o conceito de cronotopo. Práxis Educativa (impresso), v. 15, p. 1-21, 2020.

COUTO, Edvaldo Souza; COUTO, Edilece Souza; CRUZ, Ingrid de Magalhães Porto. \#Fiqueemcasa: educação na pandemia da covid-19. Interfaces Científicas, Aracaju, v. 8, n. 3, p. 200, 2020. Disponível em: https://periodicos.set.edu.br/ index.php/educacao/article/view/8777/3998. Acesso em: 22 jul. 2020.

CRUZ, R. P. Covid-19: "Reabrir as escolas agora é genocídio", diz pesquisador da FGV. R7, 2020. Disponível em: https://noticias.r7.com/saude/covid-19-reabrir-as-escolas-agora-e-genocidio-diz-pesquisador-da-fgv-15072020. Acesso em: 23 jul. 2020.

DIAS, Erika; PINTO, Fátima C. F. A Educação e a Covid-19. Ensaio: Avaliação e Políticas Públicas em Educação, Rio de Janeiro, v. 28, n. 108, p. 545-554, jul./ set. 2020 .

FERREIRA, Renilze B. A. S.; SILVA, Ivanda M. M. "Didática" no contexto da educação a distância: quais os desafios? Revista Brasileira de Aprendizagem Aberta e a Distância, v. 8, 2009. Disponível em: http://seer.abed.net.br/index. php/RBAAD/article/view/217. Acesso em: 24 jul. 2020. 
GIL, Antonio Carlos. Como elaborar projetos de pesquisa. 4. ed. São Paulo: Atlas, 2008.

KENSKI, V. M. Avaliação e acompanhamento da aprendizagem em ambientes virtuais a distância. In: MILL, D. R. S.; PIMENTEL, N. M. (orgs.). Educação a distância: desafios contemporâneos. São Carlos: EdUFSCar, 2010.

NÓVOA, A. (Org.). Os professores e sua formação. Lisboa: Dom Quixote, 1992.

MARQUES, Romualdo. A ressignificação da educação e o processo de ensino e aprendizagem no contexto de pandemia da covid-19. Boletim de Conjuntura (Boca), ano II, v. 3, n. 7, p. 31-46. Boa Vista, 2020. Disponível em: https://revista. ufrr.br/boca/article/view/Marques/3000. Acesso em: 24 jul. 2020.

MEC. Ministério da Educação. Coronavírus: monitoramento das instituições de ensino. 2020a. Disponível em: http://portal.mec.gov.br/coronavirus/. Acesso em: 28 set. 2020 .

MEC. Portaria n ${ }^{\circ}$ 343, de 17 de março de 2020. Diário Oficial da União - Imprensa Nacional [Internet]. 2020b. Disponível em: http://www.in.gov.br/en/ web/dou/-/portaria-n-343-de-17-de-marco-de-2020-248564376. Acesso em: 20 jul. 2020.

OLIVEIRA, Eleilde de Souza et al. A educação a distância (EaD) e os novos caminhos da educação após a pandemia ocasionada pela Covid-19. Brazilian Journal of Development, v. 6, n. 7, p. 52860-52867, 2020.

ONU. Transformando nosso mundo: a agenda 2030 para o desenvolvimento sustentável. 2015. Disponível em: https://nacoesunidas.org/pos2015/agenda2030/. Acesso em: 10 dez. 2020.

PIMENTA, Selma Garrido. Epistemologia da prática ressignificando a didática. In: FRANCO, Maria Amélia Santoro; PIMENTA, Selma Garrido (Org.). Didática: embates contemporâneos. São Paulo: Loyola, 2010. p. 15-41.

PINHEIRO, Chloé; RUPRECHT, Theo. Coronavírus: primeiro caso é confirmado no Brasil. O que fazer agora? Veja Saúde, São Paulo, Saúde. Publicado em 26 fev. 2020. Atualizado em 18 ago. 2020. Disponível em: https://saude.abril.com. br/medicina/coronavirus-primeiro-caso-brasil/. Acesso em: 29 jun. 2020.

PRENSKY, Marc. Nativos digitais, imigrantes digitais. Tradução de Roberta de Moraes Jesus de Souza. On the Horizon, NCB University Press, v. 9, n. 5, out. 2001. Disponível em: http://www.colegiongeracao.com.br/novageracao/2_intencoes/nativos.pdf. Acesso em: 21 out. 2020. 
TARDIF, M. Saberes docentes e formação profissional. Petrópolis: Vozes, 2002.

UOL. Covid: com 1.346 novas mortes em 24 h, Brasil chega a 81.597 óbitos. 2020. Disponível em: https://noticias.uol.com.br/saude/ultimas-noticias/redacao/2020/07/21/coronavirus-covid-19-casos-mortos-21-julho.htm. Acesso em: 22 jul. 2020. 